\title{
Le Codex Mariendalensis, texte fondateur de la littérature luxembourgeoise
}

Jean Portante

\section{OpenEdition}

12 Journals

Édition électronique

URL : http://journals.openedition.org/rbnu/694

DOI : $10.4000 /$ rbnu. 694

ISSN : 2679-6104

Éditeur

Bibliothèque nationale et universitaire de Strasbourg

Édition imprimée

Date de publication : 1 novembre 2017

Pagination : 76-79

ISBN : 9782859230678

ISSN : 2109-2761

\section{Référence électronique}

Jean Portante, "Le Codex Mariendalensis, texte fondateur de la littérature luxembourgeoise », La Revue de la BNU [En ligne], 16 | 2017, mis en ligne le 01 juillet 2019, consulté le 15 décembre 2020. URL:

http://journals.openedition.org/rbnu/694; DOI : https://doi.org/10.4000/rbnu.694

\section{(c) (i) (9)}

La Revue de la BNU est mise à disposition selon les termes de la Licence Creative Commons Attribution - Pas d'Utilisation Commerciale - Partage dans les Mêmes Conditions 4.0 International. 


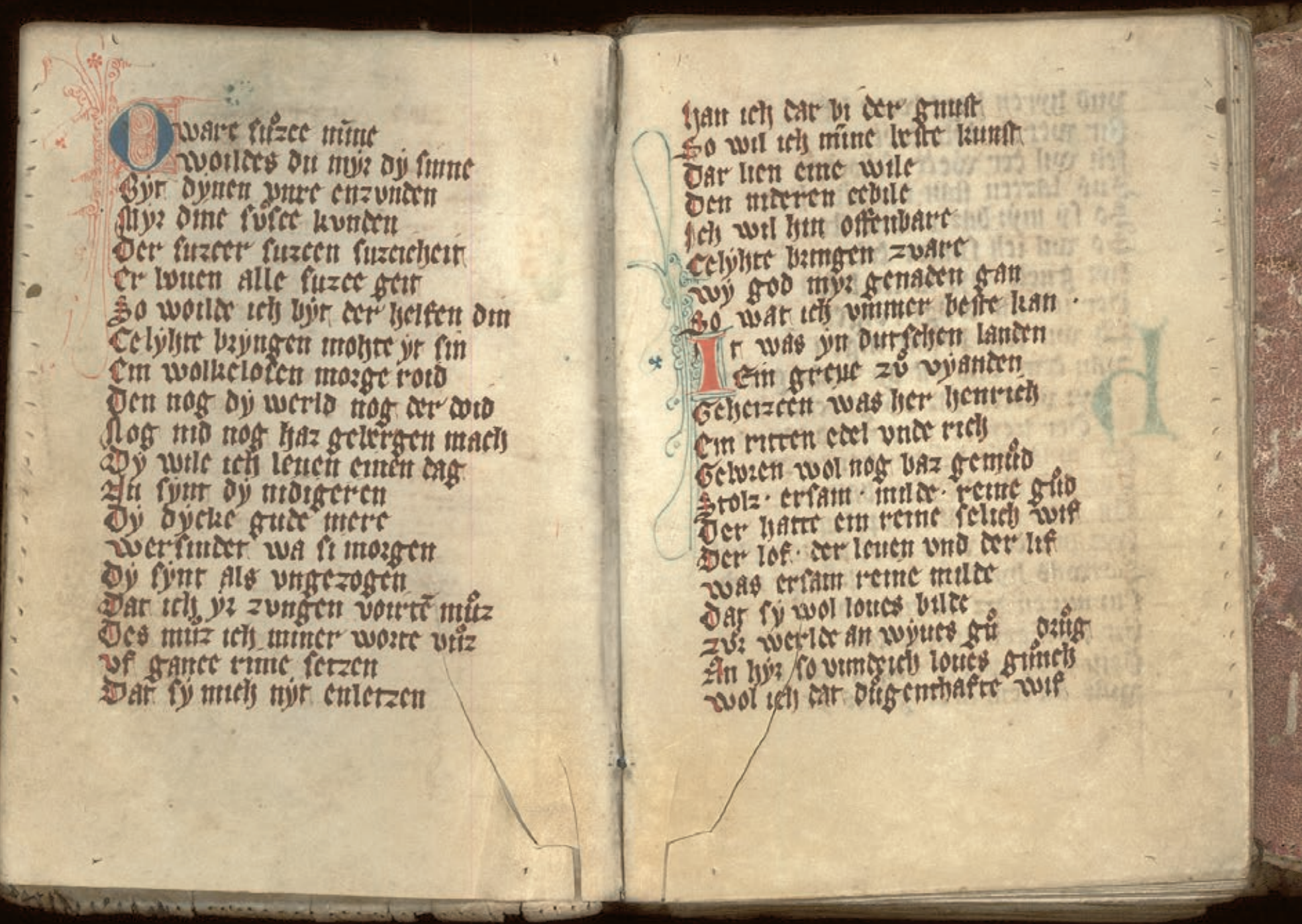




\section{LUXEMBOURG \\ LE CODEX MARIENDALENSIS, TEXTE FONDATEUR DE LA LITTÉRATURE LUXEMBOURGEOISE

\author{
PAR JEAN PORTANTE
}

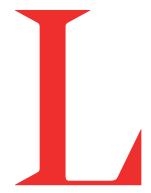

ongtemps on a cru, au Luxembourg, et fait croire, que le premier ouvrage littéraire digne de ce nom, faisant couler le parler luxembourgeois dans l'écriture poétique, était $E$ Schreck op de lëtzebuerger Parnassus (Un pas sur le Parnasse luxembourgeois) d'Antoine Meyer, publié en 1829 - ce qui, par comparaison avec d'autres pays, dénotait une naissance assez tardive de la littérature dans notre pays, sans tradition, en somme. Ni médiévale ni classique. Ce qu'on ne savait pas, ou plus, surtout au $20^{\mathrm{e}}$ siècle, parce qu'on l'avait oublié, c'est que bien avant qu'Anton Meyer ne donne, timidement, des lettres de noblesse à la langue luxembourgeoise, un autre texte, une chanson de geste de quelque 6000 vers, dormait un long sommeil au fond de quelque bibliothèque, réveillée de temps à autre par des érudits, la dernière fois, partiellement semble-t-il, et sans qu'on en mesure l'importance, en 1931, avant d'être déclarée un peu hâtivement perdue à tout jamais.

C'était sans compter sur l'acharnement du chercheur Guy Berg qui (suivant après bien d'autres fouineurs le cheminement de ceux qui, tels par exemple
Pierre Grégoire, étaient revenus bredouilles de leur quête) a fini par mettre la main, le 6 novembre 1999, sur le manuscrit en parchemin de ce qu'on appelle le Codex Mariendalensis, à savoir le récit épique en vers de la vie de la comtesse Yolanda de Vianden. Tandis que ceux qui l'avaient précédé dans la quête de ce Graal de la littérature luxembourgeoise pensaient que l'errance du manuscrit avait connu de rocambolesques aventures, Berg finit par dénicher le trésor dans la bibliothèque du château d'Ansembourg... à un jet de pierre du lieu où il avait été composé.

Cela dit, l'histoire en tant que telle de la comtesse Yolanda (1231-1283) - celle d'une femme, née à Vianden, dans la partie septentrionale du Luxembourg actuel, bravant les interdits de son temps et se réfugiant, pour échapper au mariage arrangé, au couvent de Marienthal, tenu alors par des sœurs dominicaines n'était point restée inconnue au fil des siècles ${ }^{1}$. Seul se cachait le manuscrit, attribué au moine dominicain Hermann von Veldenz qui l'aurait écrit dans la toute fin du $13^{\mathrm{e}}$ siècle, voire au début du $14^{\mathrm{e}}$. Au moment même où naissaient des chansons de geste fondatrices un peu partout en Europe, Hermann forgeait le premier 
texte littéraire en francique mosellan, c'est-à-dire en proto-luxembourgeois ${ }^{2}$ - un texte donné pour perdu donc, voire détruit, mais qui avait inspiré maint érudit, et parmi eux le père jésuite Alexander Wiltheim qui, en 1655, était le dernier à avoir eu le manuscrit entier entre ses mains quand il se mit à le recopier, puis à le traduire en latin ${ }^{3}$.

C'est cette version latine qui servira de point de départ aux traducteurs et exégètes successifs le faisant passer vers l'allemand, le français ou l'anglais. Comme si une malédiction pesait sur l'épopée, la transcription en francique de Wiltheim, qui aurait dû se trouver aux archives de l'archevêché de Prague, avait disparu à son tour. D'elle ne subsistent que les traces laissées par les éditions de Franz Pfeiffer (en 1866) et John Meier (en 1889), qui ont "adapté " le texte de Hermann transcrit par Wiltheim pour le rendre lisible aux goûts du $19^{\mathrm{e}}$ siècle, effaçant mainte spécificité de la langue de l'original afin de mieux faire passer l'histoire passionnante de Yolanda. Le texte a ainsi perdu sa valeur principale de témoin précieux de l'état du francique mosellan à la fin du Moyen Âge.

Aujourd'hui, on peut dire que l'épopée de Yolanda de Vianden est le texte fondateur de la littérature d'expression luxembourgeoise, pour au moins trois raisons - linguistique, historico-culturelle et littéraire -, comme le souligne Guy Berg. Elle offre aux sciences du langage et aux médiévistes spécialisés dans le moyen haut allemand la possibilité d'étudier plus en profondeur l'évolution de la langue dans l'aire linguistique du francique mosellan, et comble ainsi une grande lacune, d'autant qu'elle est probablement le seul document de cette envergure rédigé en francique mosellan occidental de l'époque, l'idiome véhiculaire étant, y compris au couvent de Marienthal, le latin. C'est par conséquent aussi l'un des rares textes décrivant les mœurs et le contexte historique, culturel et spirituel, à la fois dans les comtés et les châteaux impliqués, ceux de Vianden et de Luxembourg en l'occurrence, et dans les couvents de la région.

Du point de vue littéraire, dans un territoire où, contrairement à d'autres contrées germaniques ou romanes, la production de textes était plus que parcimonieuse, le Codex, tout en faisant figure d'exception, ne s'en inscrit pas moins dans une parenté avec les chansons de geste françaises et allemandes, voire avec les productions des « Minnesänger ", la variante allemande de l'amour courtois des troubadours, dont les prototypes sont le Parzival de Wolfram von Eschenbach, les œuvres de Walther von der Vogelweide ou le Tristan de Gottfried von Strassburg. On retrouve en effet dans le récit épique de la vie de Yolanda et ceci prouve que Hermann était au fait de ce qui s'écrivait à son époque - bien des traits communs à la structure du Minnesang, dont l'obstacle, en tant que retardement, est une des caractéristiques. Ainsi, de même que Parzival, Yolanda est de noble extraction, et comme la comtesse, le héros à la recherche du Graal est empêché par sa mère de vivre sa vie, celle de chevalier pour ce dernier, de religieuse dans le cas de Yolanda. Or tous les deux feront une première tentative de passer outre, alors qu'ils sont très jeunes encore, tentative vouée à l'échec les condamnant, de longues années durant, à ronger leur frein.

Ces parallélismes avec bien des chansons de geste et des textes de Minnesänger ouvrent un vaste champ à la critique littéraire qui, en ce qui concerne le Codex, n'en est qu'à ses débuts. D'autant plus intéressant est alors de constater que, chez Hermann, le personnage central est une femme. Une femme se révoltant contre la société patriarcale qui l'entoure, cette société qui voulait qu'une noble de son rang doive être mariée à son égal, non par amour mais pour des raisons bassement matérielles d'extension de territoire, et donc de domination politico-militaire. Yolanda a quatorze ans, raconte Hermann, quand, rendant visite avec sa mère Marguerite de Courtenay et l'homme qui lui est destiné, à savoir Valeran $\mathrm{I}^{\mathrm{er}}$ de Monschau, au couvent de Marienthal, elle fausse compagnie aux siens et se réfugie au sein de la communauté monastique. Prise de court, Marguerite se rend au château de Luxembourg pour solliciter le secours armé de la comtesse Ermesinde. Elle revient avec des hommes armés, menaçant de réduire en cendres le monastère si sa fille n'est pas rendue à sa famille. Yolanda, forcée de se plier à l'ordre social, refusant toutefois le mariage, finira bien plus tard par faire céder les siens et entrera définitivement à Marienthal, y devenant par la suite la prieure.

Ce dénouement fait chavirer la logique du Minnesang classique et entrer le récit dans l'hagiographie, l'amour contrarié si caractéristique de la chanson 
de geste étant celui que Yolanda porte à Jésus. Du coup transparaît le dessein premier du frère Hermann, celui de faire, dirait-on aujourd'hui, du lobbying pour que Yolanda, qui a agi en sainte, soit canonisée après sa mort. Nous voilà à cheval sur deux genres : dans l'archétype des contes médiévaux d'un côté, dans la vie des saints de l'autre, ce genre dont la littérature médiévale fut si friande.

Le Codex Mariendalensis est conservé aujourd'hui, après avoir été acquis par l'État luxembourgeois, dans la réserve précieuse de la Bibliothèque nationale de Luxembourg ${ }^{4}$. C'est là qu'il attend désormais les chercheurs et les curieux que pendant plus de sept cents ans il a nargués.

\section{NOTES}

1- Le dernier livre à en témoigner est le roman historique Yolanda, de Waltraud Riehm, paru en 2007 aux éditions Paulinus, à Trèves.

2- Il s'agit plus précisément du francique mosellan occidental qui s'étendait jusqu'à la frontière de la Sarre.

3- Alexander Wiltheim, Vita venerabilis Yolandae priorissae ad Mariae vallem in ducatu Luciliburgensi cum appendice de Margarita Henrici VII. Le texte latin de Wiltheim a été publié en 2007 en versions allemande et anglaise par Guy Berg et Gerald Newton.

4- Le texte original est disponible sous forme de livre, grâce à l'édition de Claudine Moulin : Bruder Hermann von Veldenz: Leben der Gräfin Yolanda von Vianden. Textgetreue Edition des Codex Mariendalensis, édité par l'Institut grand-ducal en 2009. 